\title{
DỤ ĐOÁN LỰC NGHIỀN ÉP TRUNG BÌNH CỦA ỐNG ĐA TẾ BÀO HÌNH VUÔNG CH!̣U TẢI DỌC TRỤC
}

\author{
TRÀN TRỌNG NHÂN \\ Truoòng Đại học Công nghiệp Thành phố Hồ Chí Minh; \\ trantrongnhan@iuh.edu.vn
}

Tóm tắt. Công thức lý thuyết cho lực ép trung bình của ba cấu trúc hình vuông đa tế bào được xây dựng bằng cách sử dụng lý thuyết Simplified Super Folding Element (SSFE). Biên dạng của cấu trúc bao gồm những phần tử cơ bản: phần tử hình vuông, hình chữ $\mathrm{T}, 3$-panel, và hình chữ thập. Mô phỏng (FEA) được thực hiện cho những cấu trúc này và chỉ ra rằng cấu trúc số I là cấu trúc tốt nhất. Đối với hai cấu trúc, sự tạo nếp ổn định và phát triển không ngừng được tạo ra. Các công thức lý thuyết cũng đồng ý với kết quả FEA.

\begin{abstract}
Theoretical analysis to average crushing load of the two multi-cell square structures are built using the Simplified Super Folding Element (SSFE) theory. The structures' profiles compose of several basic angle elements: right corner, T-shape, 3-panel, and criss-cross angle element. Finite element analyses (FEA) are performed for these structures and point out that the structure I is the best structures. For two structures, the stable and progressive collapse are generated. The theoretical solutions are used to validate the FEA results.
\end{abstract}

Từ khóa: Năng lượng hấp thụ, Lực ép trung bình, Ống hình vuông

\section{LỜI MỞ ĐẦU}

Cấu trúc thành mỏng đa tế bào được sử dụng rộng rãi để trở thành thiết bị hấp thụ năng lượng va đập trong thiết kế xe trong nhiều thập niên vì giá tương đối rẻ và hiệu suất trọng lượng tốt hơn. Nghiên cứu ban đầu nhằm khảo sát cơ chế biến dạng cấu trúc dưới tải dọc trục. Những tác giả đi tiên phong trong nghiên cứu thực nghiệm và lý thuyết của ống thành mỏng chịu tải tỉnh và động dọc trục như Wierzbicki and Abramowicz [1], Abramowicz and Jones [2], và Guillow và cộng sự [3].

Cơ chế biến dạng của ống hình vuông khác với ống hình tròn. Các ống hình vuông biến dạng với kiểu không đối xứng, đối xứng, hoặc uốn cong, trong khi các ống tròn có bốn chế độ biến dạng là diamond, hỗn hợp và uốn. Những gì xuất hiện trong quá trình biến dạng chủ yếu phụ thuộc vào tỷ lệ độ dày đường kính-chiều dài của ống tròn. Tuy nhiên, các đặc tính chung của biểu đồ lực-chuyển vị của ống vuông tương tự như các ống tròn [4]. Những biểu đồ này cho thấy lực nghiền đầu tiên đạt tới đỉnh, sau đó giảm và dao động xung quanh giá trị của lực nghiền trung bình.

Theo lý thuyết Super Folding Element (SFE) được đề nghị bởi Wierzbicki and Abramowicz [1], những phần tử biến dạng đã được mô tả trong một số cơ chế biến dạng chính bao gồm kiểu không mỏ rộng, gần như mở rộng, và mở rộng. Khía cạnh chính của lý thuyết SFE là việc công nhận sự hình thành các đường bản lề di chuyển xác định ranh giới của các thành phần hình thang, hình xuyến, hình nón và hình trụ bề mặt trong quá trình ép dọc trục.

Chen và Wierzbicki [5] đã đơn giản hóa lý thuyết SFE để nghiên cứu ứng xử dọc trục của các ống hình vuông đơn, đa tế bào, và ống điền đầy bọt foam. Bằng cách chia mặt cắt ngang của ống thành các phần tử, và giả thiết rằng mỗi phần tử đóng góp vai trò tương tự trong cấu trúc sau khi biến dạng, công thức lý thuyết cho lực nghiền trung bình được phát triển. Công trình của Chen và Wierzbicki chỉ ra rằng việc bổ sung các bức tường bên trong làm cho sự hấp thụ năng lượng riêng (SEA) tăng khoảng $15 \%$ so với ống đơn. 
Kim [6] đã áp dụng lý thuyết của [5] cho các ống đa tế bào với bốn phần tử vuông ở góc dưới tải động. SEA của cấu trúc đa tế bào được báo cáo tăng $190 \%$ so với ống đơn hình vuông. Zhang và cộng sự [7] cũng đã sử dụng lý thuyết của [5] để xây dựng được công thức lý thuyết cho lực nghiền trung bình của các ống vuông đa tế bào ở điều kiện tải trọng động. Trong công trình của Zhang và cộng sự, tiết diện của ống được chia thành ba phần tử cơ bản, và nghiên cứu của họ cũng đo sự đóng góp của từng loại phần tử đối với sự hấp thụ năng lượng biến dạng dẻo qua biến dạng màng tế bào. Các công thức lý thuyết giả định một bước sóng trung bình cho các nếp gấp không giống nhau được phát triển ở các góc. Ngoài ra, mô hình của [5] cũng được áp dụng bởi Hanssen và cộng sự [8] để dự đoán lực nghiền trung bình của cấu trúc ống phức tạp khác. Najafi và Rais-Rohani [9] mở rộng lý thuyết SFE để khảo sát các đặc tính nghiền của các ông đa tế bào. Ngoài ra, các Ứng xử ống hình vuông và hình tròn mỏng dưới tải động dọc trục cũng đã được nghiên cứu bởi Jensen và công sự [10].

Trên tất cả, ứng xử của những cấu trúc đa tế bào hình vuông được nghiên cứu trên cả hai phương diện lý thuyết và mô phỏng. Dựa trên lý thuyết SSFE, các công thức lý thuyết của lực nghiền trung bình cho cấu trúc đa tế bào được đề nghị. Tất cả cấu trúc nghiên cứu được chia thành nhiều phần tử góc, là hình chữ nhật, 3-panen, hình chữ $\mathrm{T}$, hình chữ thập chéo và phần tử góc 4-panel. ANSYS / LS-DYNA được sử dụng để mô phỏng các cấu trúc. Những biểu thức lý thuyết được sử dụng để xác nhận kết quả của mô phỏng.

\section{PHÂN TÍCH LÝ THUYÊT}

\subsection{Phân tích lý thuyết đối với cấu trúc đa tế bào}

Lý thuyêt SSFE được áp dụng cho cấu trúc hình vuông đa tế bào I và II trong Hình 1 . Lý thuyết này giả định rằng độ dày của thành ống là hằng số, và sự thay đổi của bước sóng $2 \mathrm{H}$ đối với thùy khác nhau được bỏ qua trong phân tích. Để phân tích sự hấp thụ năng lượng qua sự hình thành của của một thùy, biên dạng của cấu trúc được chia thành các phần tử cơ bản: phần tử góc vuông, 3-panel, hình chữ T, và hình chữ thập.

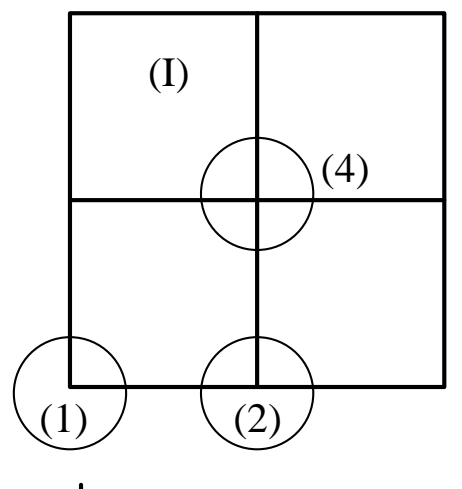

(1)


Hình 1. Cấu trúc đa tế bào và phần tủ cơ bản

Nguyên lý cân bằng năng lượng phát biểu rằng công của ngoại lực để tạo thành một thùy hoàn toàn là bằng tổng năng lượng hấp thụ qua uốn và và biến dạng màng. Đó là

$P_{m} 2 H=\frac{1}{\eta}\left(E_{b}+E_{m}\right)$

trong đó $\mathrm{P}_{\mathrm{m}}, \mathrm{E}_{\mathrm{b}}$ và $\mathrm{E}_{\mathrm{m}}$ là lực nghiền trung bình, năng lượng uốn và năng lượng màng. $2 \mathrm{H}$ và $\eta$ là chiều cao của thùy và hệ số nghiền hiệu quả. Trong thực tế, panel của thùy sau biến dạng không hoàn toàn phẳng như được mô tả trong Hình 2. Do đó, khoảng cách nghiền có sẵn nhỏ hơn $2 \mathrm{H}$. Abramowicz and Wierzbicki [1] cho thấy hệ số nghiền hiệu quả thay đổi trong khoảng $0,7-0,75$. Trong trường hợp này, giá trị của $\eta$ được đề nghị là 0,7 . 


\subsubsection{Năng lượng uốn}

Năng lượng uốn $\mathrm{E}_{\mathrm{b}}$ của mỗi panel có thể được xác định bằng cách tổng hợp năng lượng hấp thụ tại đường bản lề dẻo. Khi đó

$E_{b}^{p}=\sum_{i=1}^{m} 2 \pi M_{0} b_{i}$

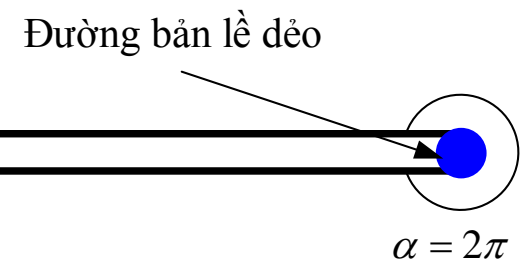

Hình 2. Đường bản lè̀ dẻo và góc quay

với b là chiều dài đường bản lề dẻo. $M_{0}=\sigma_{0} t^{2} / 4$ là mô men uốn dẻo toàn phần. $2 \pi$ là góc uốn tại đường bản lề. Vì mỗi panel chia sẻ cùng một vai trò và cấu trúc đa tế bào được tạo ra bởi m panel (Hình 1), năng lượng uốn của cấu trúc vuông đa tế bào có thể được ước tính như sau

$E_{b}^{\text {structure }}=2 \pi M_{0} B$

với $\mathrm{B}$ là tổng của các chiều dài đường bản lề.

\subsubsection{Năng lượng biến dạng màng}

\subsubsection{Năng lượng biến dạng màng của phần tử góc vuông}

Để xác định năng lượng màng của góc vuông biến dạng thông qua kiểu đối xứng trong lý thuyết SSFE, phần tử thùy cơ bản được hình thành bởi các phần tử hình tam giác và đường uốn bản lề (Hình 3 (a)). Năng lượng hấp thụ trong màng của một panel có thể được ước tính bằng cách tích phân vùng tam giác (vùng gạch chéo trong Hình 3 (a)) như sau

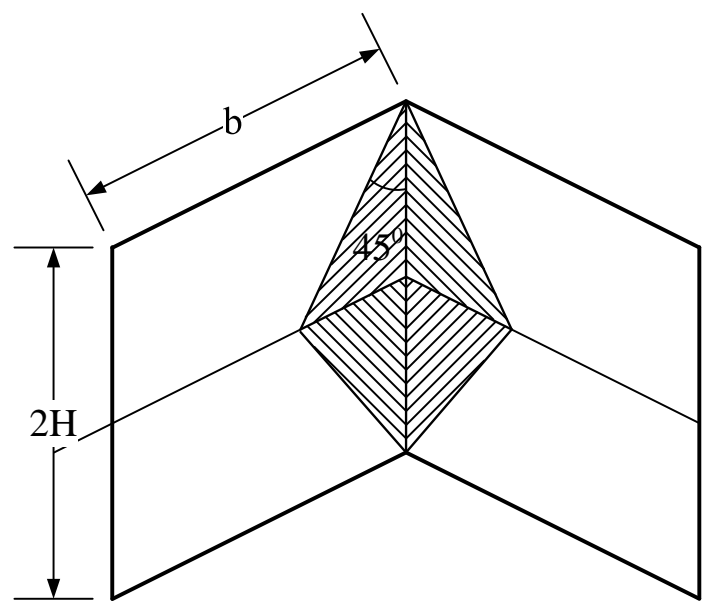

(a)



(b)

Hình 3. Biến dạng của phần tử góc vuông: a) kiểu đối xứng và b) kiểu phi đối xứng

$E_{m}^{s y m-p}=\int \sigma_{0} t d s=\sigma_{0} t H^{2}=4 M_{0} \frac{H^{2}}{t}$

Vì mỗi panel có vai trò tương tự trong phần tử góc nên năng lượng biến dạng màng của phần tử góc vuông kiểu đối xứng là gấp đôi năng lượng biến dạng màng của một panel, như thế

$E_{m}^{s y m-r c}=8 M_{0} \frac{H^{2}}{t}$ 
Năng lượng biến dạng màng của phần tử góc vuông trong trường hợp biến dạng phi đối xứng đã được phân tích bởi Chen và Wierzbicki [5]. Và nó được xác định như sau

$$
E_{m}^{a s y m-r c}=4 M_{0} \frac{H^{2}}{t}
$$

\subsubsection{Năng lượng biến dạng màng của phần tử 3-panel và hình chữ $T$}

Cấu trúc của phần tử hình chữ $\mathrm{T}$ được tạo thành bởi một phần tử góc vuông và một panel bổ sung (Hình 4). Theo đó, năng lượng biến dạng màng của phần tử hình chữ $\mathrm{T}$ có thể được tính bằng tổng năng lượng màng của phần tử góc vuông của kiểu biến dạng đối xứng và năng lượng màng của panel bổ sung. Như thế

$$
E_{m}^{T-\text { shape }}=3 E_{m}^{s y m-p}=12 M_{0} \frac{H^{2}}{t}
$$

Năng lượng biến dạng màng của phần tử 3-panel được tính bởi Zhang và Zhang [11], và được tính theo công thức

$$
E_{m}^{3-\text { panel }}=4 M_{0} \frac{H^{2}}{t}(1+2 \tan (\phi / 2))
$$
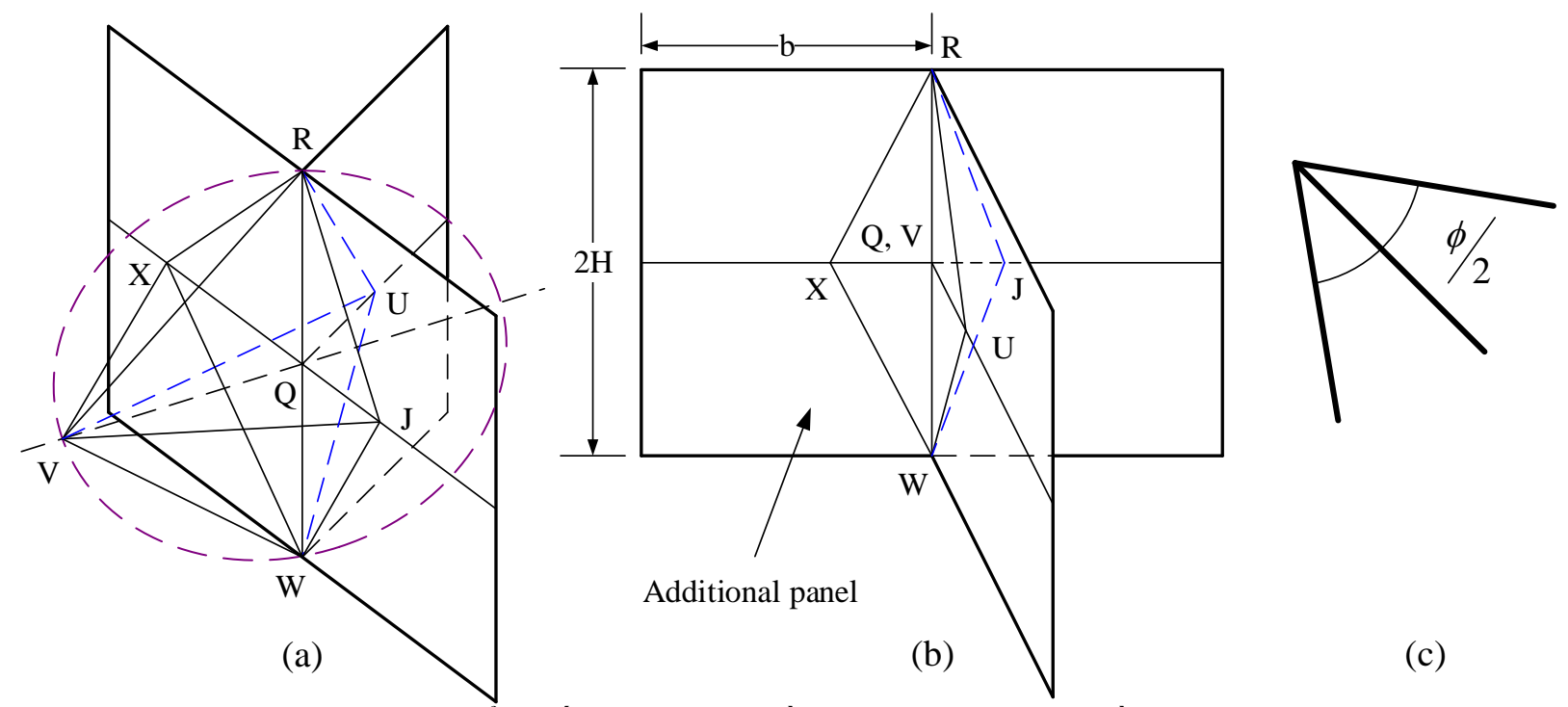

Hình 4. a, b) Kiểu biến dạng của phần tử T-shape và c) phần tử 3-panel

\subsubsection{Năng lượng biến dạng màng của phần tử hình chữ thập}

Là một cấu trúc đối xứng và được hình thành bởi bốn panel, sự hấp thụ năng lượng trong biến dạng màng của phần tử chữ thập được xác định bởi tổng năng lượng biến dạng màng hấp thụ bởi tất cả bốn panel (Hình 5). Giả thiết rằng các phần tử góc đóng góp vai trò tương tự trong cấu trúc, bốn panel tạo ra hai phần tử góc vuông, và kiểu biến dạng của phần tử góc vuông là đối xứng. Do đó, năng lượng biến dạng màng của phần tử chữ thập là

$$
E_{m}^{c-c}=2 E_{m}^{s y m-r c}=16 M_{0} \frac{H^{2}}{t}
$$




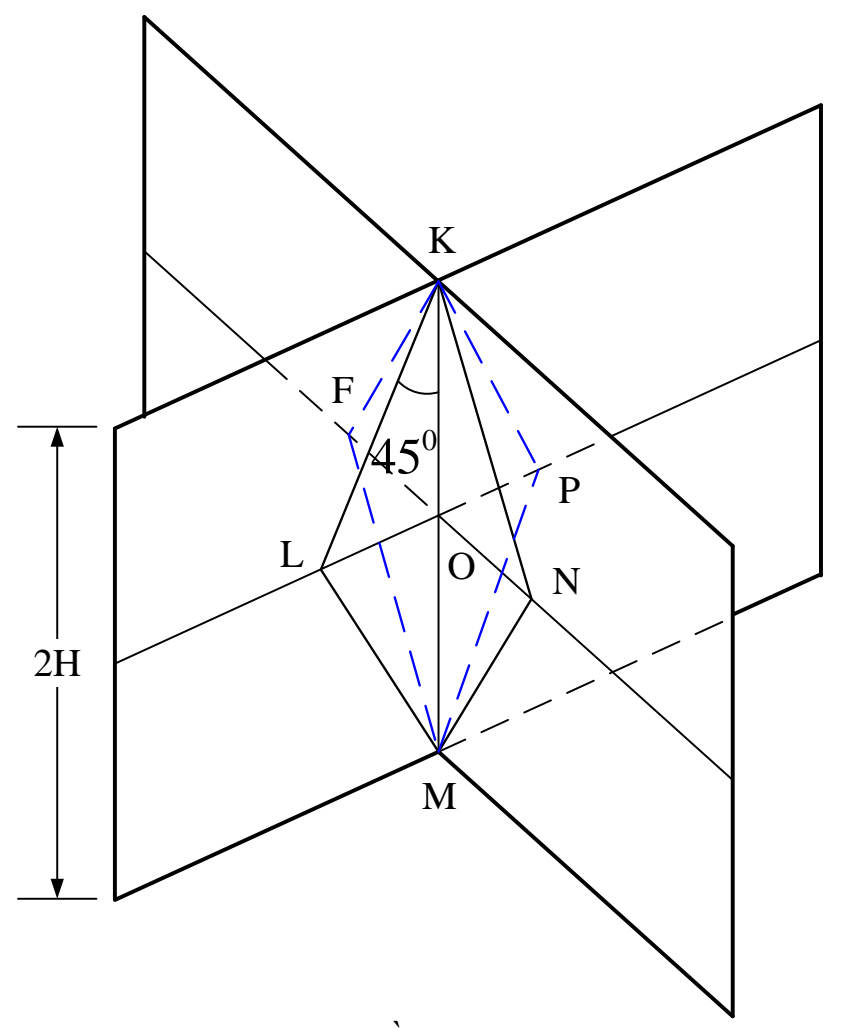

Hình 5. Phần tử chĩ thập

\subsubsection{Lực nghiền trung bình của cấu trúc}

Biên dạng của cấu trúc I được hình thành bởi sự kết hợp giữa bốn phần tử góc vuông, bốn hình chữ $T$ và một phần tử góc chéo (Hình 1 (a)). Thay thế các công thức trong phương trình. (3), (5), (7), (9) vào phương trình. (1), biểu thức đề xuất của lực nghiền trung bình của cấu trúc I như sau

$$
P_{m-I} 2 H \eta=2 \pi M_{0} B+2 M_{0} \frac{H^{2}}{t}(16+24+8)
$$

Một nửa chiều cao thùy được xác định bởi điều kiện tĩnh là $\partial P_{m} / \partial H=0$. Như thế

$H=\sqrt{\frac{\pi B t}{48}}$

Thay công thức (11) vào (10), lực nghiền trung bình của cấu trúc I là

$P_{m-I}=\sigma_{0} \pi^{0.5} B^{0.5} t^{1.5} \frac{2 \sqrt{3}}{\eta}$

Cấu trúc ống II được hình thành bởi bốn phần tử 3-panel và một phần tử chữ thập. Thay thế năng lượng biến dạng uốn và màng của những góc phần tử này vào công thức (1), ta được

$P_{m-I I} 2 H \eta=2 \pi M_{0} B+2 M_{0} \frac{H^{2}}{t}(16+16 \tan (\phi / 2))$

Từ điều kiện tĩnh $\partial P_{m} / \partial H=0$, nửa chiều cao của thùy $\mathrm{H}$ được tính theo công thức

$H=\sqrt{\frac{\pi B t}{16+16 \tan (\phi / 2)}}$ 
là

Kết hợp công thức (13) và (14), ta được công thức xác định lực nghiền trung bình lên cấu trúc II

$$
P_{m-I}=\sigma_{0} \pi^{0.5} B^{0.5} t^{1.5} \frac{8+8 \tan (\phi / 2)}{\eta}
$$

\subsection{Mô phỏng}

Cấu trúc đa tế bào được làm bằng hợp kim nhôm $\mathrm{AA} 6060 \mathrm{~T} 4$ với tính chất cơ học: Mô đun Young $\mathrm{E}=68200 \mathrm{MPa}$, ứng suất đàn hồi $\sigma_{\mathrm{y}}=80 \mathrm{MPa}$, ứng suất tới hạn $\sigma_{\mathrm{u}}=173 \mathrm{MPa}$, hệ số Poisson $v=$ 0,3 và hệ số $\mathrm{n}=0,23$. Đường cong ứng suất - biến dạng kỹ thuật cũng được trình bày trong tài liệu [12]. Vì hợp kim nhôm không nhạy cảm với hiệu ứng tốc độ biến dạng, hiệu ứng này bị bỏ qua trong mô hình phần tử hữu hạn.

Phần mềm ANSYS/LS-DYNA được sử dụng để mô phỏng cấu trúc đa tế bào chịu tải động dọc trục. Các cấu trúc được mô phỏng với các phần tử vỏ Belytschko - Tsay 4-node với ba điểm tích hợp thông qua độ dày và với một điểm tích hợp trong mặt phẳng phân tố. Vật liệu AA6060 T4 được mô hình hóa với mô hình vật liệu \# 24 (Mat_Piecewise_Linear_Plasticity) trong ANSYS / LS-DYNA. Đối với sự tiếp xúc của bề mặt, tiếp xúc nút-bề mặt giữa thành mỏng và tường cứng được định nghĩa để mô phỏng tiếp xúc thực. Mặt khác, một thuật toán tiếp xúc bề mặt đơn được cung cấp bởi ANSYS / LS-DYNA cũng được sử dụng để xem xét sự tự tiếp xúc giữa các phần tử vỏ. Hệ số ma sát coulomb là 0,28 trong số tất cả các bề mặt tiếp xúc đã được sử dụng. Một khối lượng $350 \mathrm{~kg}$ được gắn vào một đầu của cấu trúc để va đập vào tường cứng với tốc độ ban đầu là $12 \mathrm{~m} / \mathrm{s}$. Hình 6 và 7 cho thấy mô hình nghiên cứu cũng như kết quả mô phỏng. Kết quả mô phỏng (FEA) cho thấy cấu trúc số I là cấu trúc tốt nhất. Đối với hai cấu trúc, sự tạo nếp ổn định và phát triển không ngừng được tạo ra.

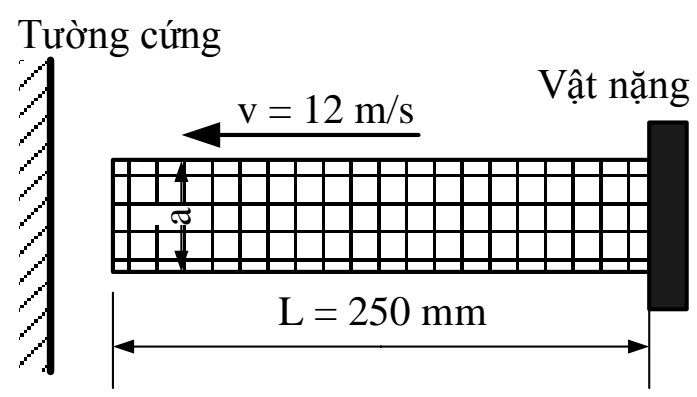

Hình 6. Mô hình nhiên cứu 




(I)
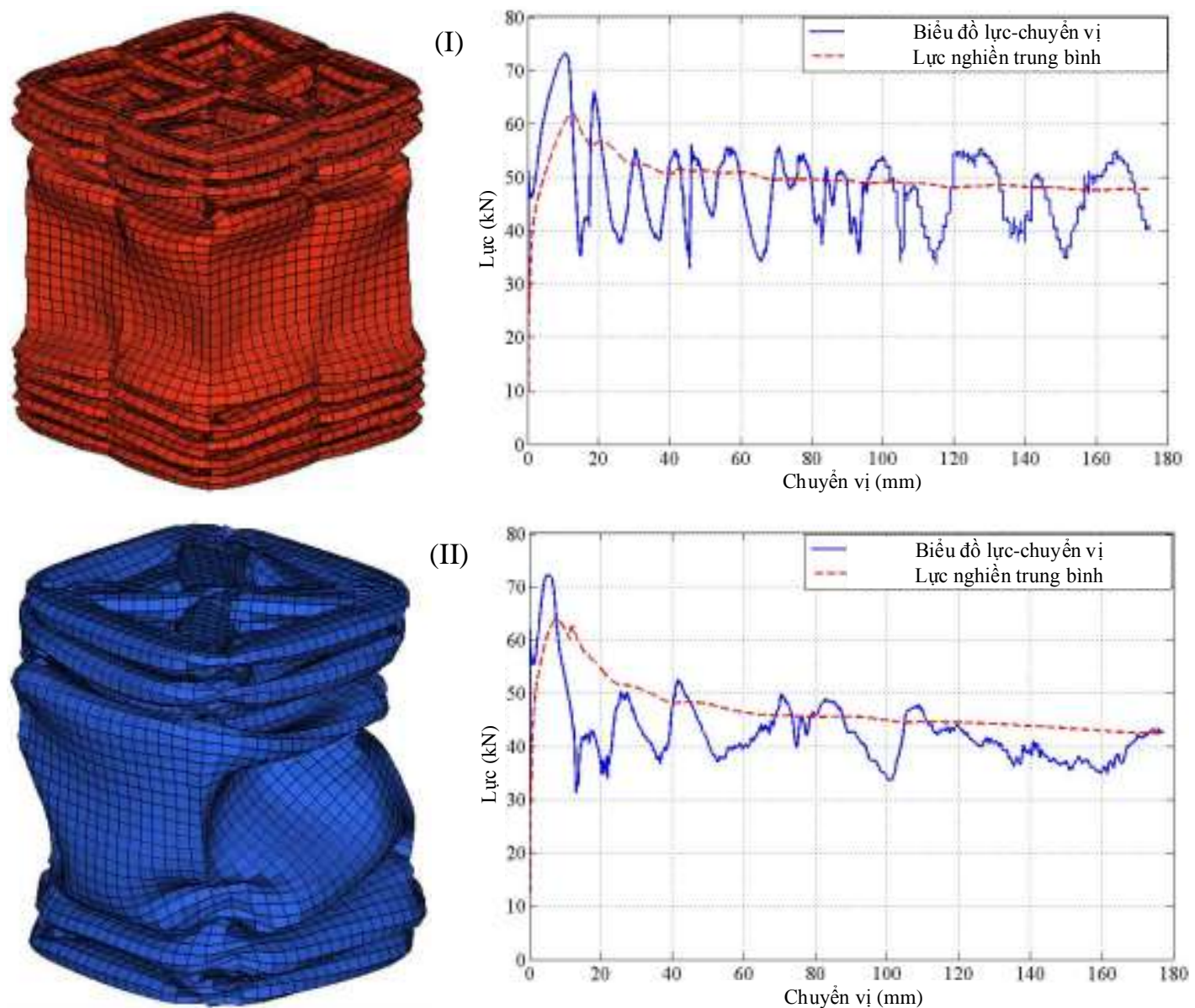

(II)

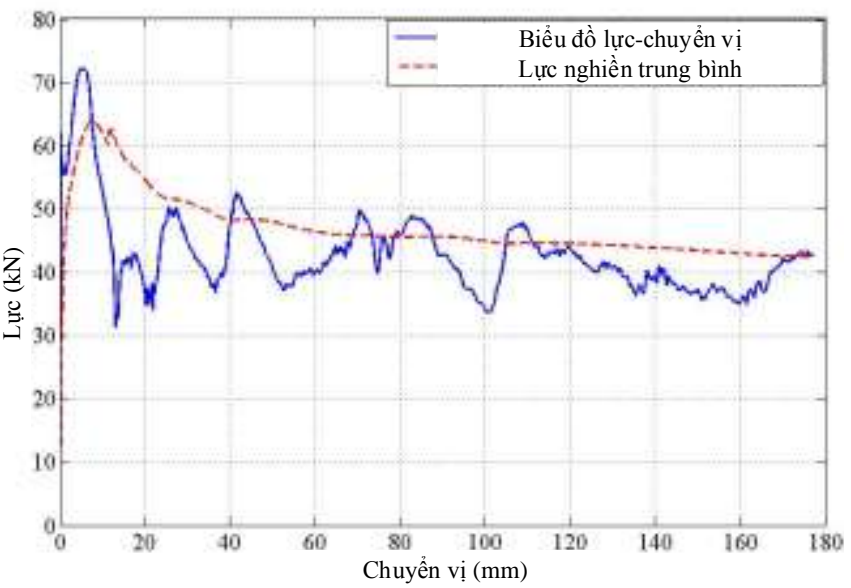

Hình 7. Biến dạng và biểu đồ lụcc-chuyển vị của cấu trúc I và II

\section{THẢO LUẬN}

Các công thức (12) và (15) của lực nghiền trung bình được tạo ra cho hai cấu trúc dưới tác dụng gần như tĩnh. Tuy nhiên, những biểu thức này không xét đến trạng thái động. Đối với các trường hợp tải trọng động, các hiệu ứng khuếch đại động bao gồm quán tính và tốc độ biến dạng phải được xem xét trong các công lý thuyết này. Thực tế, hợp kim nhôm không nhạy cảm với tốc độ biến dạng [13]. Do đó, hệ số động $\mathrm{k}$ được đề xuất để tính hiệu quả quán tính [14]. Thực sư không đơn giản để xác định một giá trị chính xác cho hệ số động, và hệ số $\mathrm{k}$ này là một biến được sử dụng cho các tham số hình học khác nhau như được mô tả bởi $[15,16]$. Theo những nghiên cứu này, hệ số $\mathrm{k}$ được đề xuất trong khoảng $1,3-$ 1,6 đối với các ống ép đùn AA6060 T4 dưới tải trọng tác động dọc trục. Để đơn giản, hệ số này được đề nghị là 1,6 đối với cả hai cấu trúc. Như vậy, công thức (12) và (15) được viết lại cho cấu trúc I và II tương ứng là

$$
\begin{aligned}
& P_{m-I}=1.6 \sigma_{0} \pi^{0.5} B^{0.5} t^{1.5} \frac{2 \sqrt{3}}{\eta} \\
& P_{m-I}=1.6 \sigma_{0} \pi^{0.5} B^{0.5} t^{1.5} \frac{8+8 \tan (\phi / 2)}{\eta}
\end{aligned}
$$
dưới đây

Trong hai phương trình trên, ứng suất chảy $\sigma_{0}$ với hệ số $\mathrm{n}=0.23$ [17] được tính theo công thức 
$\sigma_{0}=\sqrt{\frac{\sigma_{y} \sigma_{u}}{1+n}}$

Hai công thức (16) và (17) được sử dụng để dự đoán lực nghiền trung bình của cấu trúc trong trường hợp chịu tải đông dọc trục. Sau đó, giá trị của lực nghiền trung bình đối với các cấu trúc tại $50 \%$ chuyển vị được sử dụng để so sánh với các giá trị nhận được bằng từ công thức (16) - (17). Rõ ràng, các lực nghiền trung bình này được định nghĩa như là lực hằng số tương đương với chuyển vị tương ứng. Sự khác biệt giữa kết quả mô phỏng và phương trình lý thuyết trên cho tất cả các trường hợp được liệt kê trong Bảng 1 . Đối với cả hai cấu trúc, sự khác biệt giữa hai phương trình (16), (17) và kết quả mô phỏng, dao động tương ứng từ $-2.47 \%$ đến $3.45 \%$ và từ $-2.56 \%$ đến $3.26 \%$.

Bảng 1. So sánh kết quả nhận được tù̀ mô phỏng và tính toán lý thuyết

\begin{tabular}{ccccccccc}
\hline & & & \multicolumn{3}{c}{ Cấu trúc I } & \multicolumn{3}{c}{ Cấu Trúc II } \\
\cline { 5 - 9 } $\mathrm{n}$ & $\begin{array}{c}\text { Bề rộng } \\
\mathrm{a}(\mathrm{mm})\end{array}$ & $\begin{array}{c}\text { Bề dày } \\
\mathrm{t}(\mathrm{mm})\end{array}$ & $\begin{array}{c}\text { FEA } \\
\mathrm{P}_{\mathrm{m}}(\mathrm{kN})\end{array}$ & $\begin{array}{c}\text { Lý thuyết } \\
\mathrm{P}_{\mathrm{m}}(\mathrm{kN})\end{array}$ & $\begin{array}{c}\text { Chênh } \\
\text { lệch } \\
(\%)\end{array}$ & $\begin{array}{c}\text { FEA } \\
\mathrm{P}_{\mathrm{m}}(\mathrm{kN})\end{array}$ & $\begin{array}{c}\text { Lý thuyết } \\
\mathrm{P}_{\mathrm{m}}(\mathrm{kN})\end{array}$ & $\begin{array}{c}\text { Chênh } \\
\text { lệch } \\
(\%)\end{array}$ \\
\hline 1 & 50 & 1.5 & 45.62 & 45.38 & -0.52 & 37.97 & 38.27 & 0.78 \\
2 & 50 & 1.6 & 61.88 & 60.47 & -2.27 & 52.25 & 51.35 & -1.73 \\
3 & 60 & 1.3 & 45.75 & 46.31 & 1.23 & 39.75 & 40.53 & 1.98 \\
4 & 60 & 2.3 & 115.17 & 117.51 & 2.03 & 105.04 & 103.97 & -1.02 \\
5 & 70 & 1.6 & 51.11 & 50.16 & -1.86 & 39.78 & 40.66 & 2.20 \\
6 & 70 & 1.7 & 69.59 & 71.99 & 3.45 & 60.34 & 62.31 & 3.26 \\
7 & 70 & 2.4 & 98.00 & 99.43 & 1.46 & 89.95 & 87.65 & -2.56 \\
\hline
\end{tabular}

\section{KÉT LUẬN}

Biên dạng của cả hai cấu trúc được chia thành phần tử góc cơ bản là góc vuông, hình chữ $\mathrm{T}, 3-$ panel, và chữ thập. Dựa trên lý thuyết SSFE, các công lý thuyết về lực nghiền trung bình cho những cấu trúc này được phát triển trong nghiên cứu này. Các mô phỏng của cấu trúc I và II dưới tải động được thực hiện. Kết quả bằng số cho thấy sự sụp đổ ổn định và lũy tiến được phát triển cho cà hai cấu trúc. Những công thức lý thuyết dự đoán lực nghiền trung bình đã được sử dụng để xác nhận các kết quả của mô phỏng. Các công thức lý thuyết dự đoán tốt lực nghiền trung bình nhận được từ mô phỏng.

\section{TÀI LIỆU THAM KHẢO}

[1] T. Wierzbicki, W. Abramowicz, On the Crushing Mechanics of Thin-Walled Structures, Journal of Applied Mechanics 50(4a) (1983) 727-734.

[2] W. Abramowicz, N. Jones, Dynamic progressive buckling of circular and square tubes, International Journal of Impact Engineering 4(4) (1986) 243-270.

[3] S.R. Guillow, G. Lu, R.H. Grzebieta, Quasi-static axial compression of thin-walled circular aluminium tubes, International Journal of Mechanical Sciences 43(9) (2001) 2103-2123.

[4] W. Abramowicz, Thin-walled structures as impact energy absorbers, Thin-Walled Structures 41(2-3) (2003) 91107. 
[5] W. Chen, T. Wierzbicki, Relative merits of single-cell, multi-cell and foam-filled thin-walled structures in energy absorption, Thin-Walled Structures 39(4) (2001) 287-306.

[6] H.-S. Kim, New extruded multi-cell aluminum profile for maximum crash energy absorption and weight efficiency, Thin-Walled Structures 40(4) (2002) 311-327.

[7] X. Zhang, G. Cheng, H. Zhang, Theoretical prediction and numerical simulation of multi-cell square thin-walled structures, Thin-Walled Structures 44(11) (2006) 1185-1191.

[8] A.G. Hanssen, A. Artelius, M. Langseth, Validation of the simplified super folding element theory applied for axial crushing of complex aluminium extrusions, International Journal of Crashworthiness 12(6) (2007) 591-596.

[9] A. Najafi, M. Rais-Rohani, Mechanics of axial plastic collapse in multi-cell, multi-corner crush tubes, ThinWalled Structures 49(1) (2011) 1-12.

[10] Ø. Jensen, M. Langseth, O.S. Hopperstad, Experimental investigations on the behaviour of short to long square aluminium tubes subjected to axial loading, International Journal of Impact Engineering 30(8-9) (2004) 973-1003.

[11] X. Zhang, H. Zhang, Numerical and theoretical studies on energy absorption of three-panel angle elements, International Journal of Impact Engineering 46(0) (2012) 23-40.

[12] S.P. Santosa, T. Wierzbicki, A.G. Hanssen, M. Langseth, Experimental and numerical studies of foam-filled sections, International Journal of Impact Engineering 24(5) (2000) 509-534.

[13] Y. Chen, A.H. Clausen, O.S. Hopperstad, M. Langseth, Stress-strain behaviour of aluminium alloys at a wide range of strain rates, International Journal of Solids and Structures 46(21) (2009) 3825-3835.

[14] A.A.A. Alghamdi, Collapsible impact energy absorbers: an overview, Thin-Walled Structures 39(2) (2001) 189-213.

[15] M. Langseth, O.S. Hopperstad, Static and dynamic axial crushing of square thin-walled aluminium extrusions, International Journal of Impact Engineering 18(7-8) (1996) 949-968.

[16] A.G. Hanssen, M. Langseth, O.S. Hopperstad, Static and dynamic crushing of square aluminium extrusions with aluminium foam filler, International Journal of Impact Engineering 24(4) (2000) 347-383.

[17] L.L. Tam, C.R. Calladine, Inertia and strain-rate effects in a simple plate-structure under impact loading, International Journal of Impact Engineering 11(3) (1991) 349-377.

Ngày nhận bài: 30/07/2018

Ngày chấp nhận đăng: 26/09/2018 